\title{
TEORIAS DA REGULAÇÃO ECONÔMICA: UMA ABORDAGEM SEGUNDO RICHARD POSNER
}

\author{
THEORIES OF ECONOMIC REGULATION: \\ AN APPROACH ACCORDING TO RICHARD POSNER
}

JACQUELINE DO SOCORRO NERI RODRIGUES LOBÃO ${ }^{1}$

JEAN CARLOS DIAS ${ }^{2}$

\section{RESUMO}

O presente artigo tem como finalidade analisar as teorias da regulação econômica sob a ótica de Richard Posner. Foram apresentados os pressupostos básicos da teoria do interesse público, da teoria da captura e da teoria econômica da regulação. Cada teoria foi analisada a partir de críticas e observações realizadas por Richard Posner com o objetivo principal de se verificar qual das teorias apresenta uma formulação mais eficiente. Para a realização do trabalho foi utilizada pesquisa bibliográfica utilizando como método a revisão da literatura. Os resultados obtidos permitem afirmar que Richard Posner concluiu que inexiste uma teoria da regulação absolutamente eficiente e livre de críticas, porém a que mais se aproxima da eficiência é a teoria econômica da regulação.

Palavras-Chave: Teorias da regulação. Richard Posner. Eficiência.

1 Mestranda em Direito, Políticas Públicas e Desenvolvimento Regional pelo Centro Universitário do Pará- CESUPA. Pós-graduada em Perícia Criminal e Ciências Forenses pelo IPOG. Pós-graduada em Direito Público- CESUPA. Advogada. Membro do grupo de pesquisa Análise Econômica do Direito. ORCID iD: https://orcid.org/0000-0002-0678-7786. E-mail: Iobaojacqueline@gmail.com

2 Doutor em Direitos Fundamentais e Relações Sociais pela pela Universidade Federal do Pará (2006). Mestre em Instituições Jurídico-Políticas pela Universidade Federal do Pará (2002). Pós-graduado em Direito Civil e Processo Civil pela Unesa Rio de Janeiro (2000). Graduado em Direito pela Universidade Federal do Pará (1993). Atualmente é Advogado, Sócio-Sênior de Bastos \& Dias s/s, escritório especializado em Direito Empresarial. Professor de Teoria do Direito, Direito Processual Civil, Teoria Geral do Processo e Direito Econômico nos cursos de graduação e pós-graduação do Centro Universitário do Pará- CESUPA onde também coordena o Programa de Pós-graduação em Direito. Professor convidado da Escola Superior da Magistratura do estado do Pará, do Centro de Formação do Ministério Público do Estado do Pará, da Escola Superior da Advocacia, da Escola Judiciária do Tribunal de Justiça do Amapá, da Escola Judiciária do Tribunal Regional do Trabalho da 8a. Região. É membro do Instituto dos Advogados do Pará, da Associação Norte-Nodeste de Professores de Processo, do Instituto Brasileiro da Política e Direito da Informática, da Fundação Brasileira de Direito Econômico. Integra diversos Conselhos Editorais de revistas jurídicas. Membro de bancas de Concursos Públicos. Tem participado como Conferencista e Professor em diversos congressos, cursos de pós-graduação, seminários e encontros jurídicos em vários Estados brasileiros. É autor de vários livros e artigos publicados nacionalmente. ORCID iD: https://orcid.org/0000-0002-8372-9758. E-mail: jean@bastosedias.com richard posner. Revista Meritum, Belo Horizonte, vol. 15, n. 3, p. 140-156, Set./Dez. 2020. DOI: https://doi.org/ 10.46560/ meritum.v15i3.8088. 
The purpose of this paper is to analyze the theories of economic regulation from the standpoint of Richard Posner. The basic assumptions of public interest theory, catch theory and economic theory of regulation were presented. Each theory was analyzed from criticisms and observations made by Richard Posner with the main objective of verifying which of the theories presents a more efficient formulation. For the accomplishment of the work was used bibliographic research using as a method the literature review. The results obtained allow us to affirm that Richard Posner concluded that there is no absolutely efficient and critique-free theory of regulation, but the one that is closest to efficiency is the economic theory of regulation.

Keywords: Theories of regulation. Richard Posner. Efficiency.

\section{INTRODUÇÃO}

O poder coercitivo do Estado se destaca como uma das suas principais prerrogativas em face da iniciativa privada. A regulação econômica corresponde ao exercício do poder de coerção do estatal em face dos agentes econômicos com a finalidade de disciplinar o mercado.

O modelo norte-americano de política regulatória foi um dos pioneiros no mundo e o seu arcabouço teórico é importante não só para que se compreendam as questões referentes à regulação nos Estados Unidos, mas também para que essa vasta experiência no campo da regulação seja transplantada ao cenário brasileiro e aplicada às peculiaridades locais.

Em razão da importância deste modelo não só em âmbito mundial, mas também em relação à regulação realizada no Brasil, o presente trabalho irá utilizar como base teórica o modelo norte-americano, que é alicerçado fundamentalmente em duas teorias da regulação, a teoria do interesse público e a teoria econômica da regulação.

O eixo de análise de ambas as teorias estará estruturado em função do risco derivado da captura dos agentes reguladores, que, comumente, é abordado pela Análise Econômica do Direito como um dos fatores relevantes no design institucional das agências.

Para desempenhar a análise dessas teorias da regulação será realizada uma abordagem conforme a ótica de Richard Posner, tendo como fundamentação o seu artigo publicado em 1974 intitulado de "Teorias da regulação econômica", considerado, até hoje, como um texto seminal para o estudo do tema.

Assim, o principal objetivo do presente trabalho é analisar as teorias da regulação, conforme exposto por Richard Posner, para que verifique qual é a formulação que este autor apresenta para uma teoria da regulação mais eficiente face o risco da captura.

Neste sentido, será explicado o funcionamento da atuação do Estado como agente regulador, abordando o conceito de regulação econômica e quais seriam seus principais objetivos e finalidades. A seção seguinte irá apresentar o conceito de "captura" e expor a sua relevância para que seja realizada uma análise crítica a respeito das teorias da regulação.

Em seguida será realizada a apresentação dos principais fundamentos das teorias econômicas, sendo a quarta seção destinada à exposição dos pressupostos da teoria do interesse público e a quinta à teoria econômica da regulação. 
Todo o trabalho será realizado a partir de uma análise crítica fundamentada na ótica de Richard Posner, para que possam ser verificadas quais as falhas presentes nos temas abordados e quais pontos mais os aproximam da eficiência na regulação econômica. Neste sentido, a sexta seção será destinada a abordagem de uma das principais críticas realizadas por Posner no que tange as teorias da regulação, qual seja, a insuficiência de suporte empírico.

0 presente trabalho foi realizado mediante pesquisa bibliográfica, por meio do método de revisão da literatura.

\section{O ESTADO COMO AGENTE REGULADOR}

A atuação do Estado como agente regulador é alvo de estudos interdisciplinares, percorrendo principalmente as áreas da economia, direito e ciências políticas. Essa multiplicidade de instrumentos é importante para que se aborde a regulação realizada pelo Estado de forma ampla, buscando analisar como deveria se dá a regulação econômica e como ela efetivamente ocorre.

A atividade regulatória desenvolvida pelo poder público engloba primordialmente três prerrogativas, que são: a edição, a implementação e a fiscalização das normas, com as conseguintes punições em caso de descumprimento. Portanto, o Estado não atua apenas de forma passiva, ele assume uma postura ativa, impondo comportamentos aos mercados que serão regulados (OLIVEIRA, 2015, p. 137).

O conceito de regulação da atividade econômica pode ser apresentado como "o conjunto de formas indiretas de intervenção do Estado sobre a atividade econômica em oposição à intervenção direta, que é aquela do Estado enquanto empresário, isto é, enquanto ofertante de bens e serviços no mercado" (SAMPAIO, 2013, p.61).

Essa intervenção pode ser realizada de diversas formas, Posner (2004, p. 50) explica que a expressão regulação econômica "se refere a todos os tipos de impostos e subsídios, bem como aos controles legislativo e administrativo explícitos sobre taxas, ingressos no mercado e outras facetas da atividade econômica".

Essa regulação será realizada por meio das agências reguladoras, que são definidas por Thomas Merrill (1997, p. 1049) como:

The agency is a centralized source of governmental authority that can bring coordinated solutions to social and economic problems throughout its jurisdiction (which in the case of a federal agency, is the entire country). It combines all governmental powers, legislative, executive, and judicial, under one convenient roof. Its leadership is expected to be nonpolitical or at least biparti san. And its staff is expected to have the specialized information and systematic knowledge-in other words, the expertise-to comprehend complex problems and to fashion rational solutions to them ${ }^{3}$.

3 A agência é uma fonte centralizada de autoridade governamental que pode trazer soluções coordenadas para problemas sociais e econômicos em toda a sua jurisdição (que, no caso de uma agência federal, é o país inteiro). Ele combina todos os poderes governamentais, legislativos, executivos e judiciais, sob o mesmo teto. Espera-se que sua liderança não seja política ou, pelo menos, bipartidária. E espera-se que sua equipe tenha informações especializadas e conhecimentos 
Este conceito de agências reguladoras é proveniente do direito norte-americano e compreende a agência como qualquer entidade da organização administrativa distinta dos poderes Executivo, Judiciário e Legislativo (OLIVEIRA, 2015, p. 141). Contudo é imperioso destacar que ao ser importado para o Brasil, o modelo de agência foi utilizado de forma mais restrita, tendo sua natureza jurídica explicada por Sérgio Guerra (2012, p.118) como:

As agências Reguladoras brasileiras são autarquias de regime especial, possuindo autonomia em relação ao Poder Público.

O regime especial significa que à entidade autárquica são conferidos privilégios específicos, visando aumentar sua autonomia comparativamente com as autarquias comuns, sem infringir os preceitos constitucionais pertinentes a essas entidades de personalidade pública.

O surgimento das agências, tanto no Brasil quanto nos Estados Unidos ocorreu em decorrência do crescimento da regulação por parte do Estado. Existe o entendimento de que a intervenção no mercado se justifica pela finalidade de garantir o equilíbrio e afastar as práticas nocivas realizadas pelos agentes econômicos, corrigindo as falhas de mercado e garantido o equilíbrio do sistema regulado. 0 monopólio, as externalidades e a assimetria de informações podem ser citados como exemplos das principais falhas de mercado que impulsionam a necessidade de regulação estatal. 0 afastamento das falhas de mercado visa à obtenção de um equilíbrio econômico que fará com que os interesses privados sejam afastados em prol da maximização do bem estar social (CAMPOS, 2008, p.283-284).

Apesar de ser amplamente difundida a concepção de que as falhas de mercado são o principal motivo ensejador da regulação, Posner (2004, p.51) se opõe a essa posição e afirma que após quinze anos de pesquisas teóricas e empíricas inexiste qualquer comprovação que sustente essa afirmação e, que os perigos das falhas de mercado são cada vez menos relevantes.

Diante dessa divergência a política regulatória norte-americana foi precursora em apresentar teorias que abordam o tema, denominadas de teorias da regulação econômica. George Stigler (2004, p.23) explica que essas teorias visam "justificar quem receberá os benefícios e quem arcará com os ônus da regulação, qual forma a regulação tomará e quais os efeitos desta sobre a alocação de recursos".

As teorias da regulação, portanto, assumem diversas abordagens em função da possibilidade de que as normas regulatórias, de fato, estejam comprometidas não com o aperfeiçoamento das relações de mercado, mas sim com interesses de grupos que buscam favorecimentos pessoais.

Esse risco de influência no processo de formulação das normas regulatórias tem sido sistematicamente, apresentado nos estudos de Análise Econômica do Direito, como o problema da captura que será abordado na seção seguinte. 


\section{O PROBLEMA DA CAPTURA COMO EIXO PARA A ANÁLISE CRÍTICA DOS MODELOS REGULATÓRIOS}

A teoria da captura se torna o ponto de interseção entre a teoria do interesse público e a teoria econômica da regulação, que terão tópicos destinados a sua análise mais específica no presente trabalho. Isto ocorre porque a captura não se constitui como uma teoria da regulação autônoma, mas sim como uma crítica decorrente da teoria do interesse público, partindo do pressuposto de que a regulação não ocorreria com a finalidade de alcançar um bem social, mas sim que ela seria proveniente de um processo pelo qual os grupos de pressão visam alcançar seus próprios interesses.

A Análise Econômica do Direito, que possui Richard Posner como um dos seus principais expoentes, corrobora com esta perspectiva, já que para esta corrente teórica os indivíduos são maximizadores de suas próprias utilidades.

Existe ainda, dentro da Análise Econômica do Direito, uma escola de pensamento dedicada ao estudo do funcionamento do mercado político denominada de public choice (escoIha pública), no qual tem como objeto de análise o Estado e o comportamento dos indivíduos em relação a este, partindo do pressuposto de que tanto na vida pessoal quanto na pública os agentes econômicos irão agir racionalmente com a finalidade de maximizar seus próprios interesses, não sendo racional pressupor uma dicotomia do indivíduo, que no âmbito pessoal agiria voltado para seu próprio benefício, porém ao ingressar na vida pública se afastaria de seus interesses para dedicar-se exclusivamente os propósitos sociais (TULLOCK; SELDON; BRADY, 2005, p. 141).

Neste sentido, a análise feita a partir da public choice deixaria claro o porquê da impossibilidade de aplicação da teoria do interesse público, demonstrando que a captura das agências ocorreria primordialmente em razão da necessidade do agente integrante da agência capturada de maximizar suas próprias utilidades ao invés de abrir mão de possíveis vantagens pessoais em favor do interesse público.

Contudo, apesar de expressar críticas relevantes e com pressupostos antagônicos à teoria do interesse público, a teoria da captura também foi alvo de uma reformulação, já que, conforme exposto, ela não poderia ser considerada uma teoria da regulação.

O problema da captura aponta que, usualmente, o processo regulatório acaba por tutelar interesses de indivíduos ou grupos que em tese deveriam ser regulados, mas que na verdade são quem controlam a regulação. Peltzman $(2004$, p.85) explica que segundo a teoria da captura "a regulação servia ao interesse dos produtores, seja por criar cartéis em indústrias em que eles não existiriam, seja por ser incapaz de controlar o poder do monopólio".

Neste sentido, além das falhas de mercado já expostas pela teoria do interesse público, a teoria da captura veio apresentar a existência também de falhas de governo (SAMPAIO, 2013). Essa perspectiva da política regulatória torna ainda mais complexo o processo de regulação econômica e, resultou em diversas consequências. Nos Estados Unidos até mesmo o posicionamento dos Tribunais diante da regulação econômica sofreu influência dos ditames desta teoria, ao presenciar o conflito entre a regulação do mercado representar uma ameaça anticoncorrencial e a intromissão na autonomia do Estado (WILEY JR, 1986, p. 728). 
A teoria da captura possui diversas versões, a primeira delas e, mais radical, foi apresentada por marxistas e ativistas políticos e, segundo Posner (2004, p. 57) corresponde a um silogismo onde os grandes capitalistas controlam as instituições, a regulação é uma instituição, portanto a regulação é controlada pelos grandes capitalistas.

Posteriormente foi apresentada uma reformulação da teoria proposta por cientistas políticos, na qual se destacou a atuação dos grupos de interesse em processos legislativos e administrativos. Sanson (2013 p.127) conceitua esses grupos como:

Organismos presentes tanto no cenário político nacional quanto no internacional, podendo ser duradouros ou efêmeros, não limitados a questões econômicas (e. g. movimentos feministas e ambientais), e representam a quebra do monopólio partidário na formulação de demandas perante os órgãos públicos, quando se utilizam de inúmeros recursos, através da pressão, para influenciá-los na defesa de interesses próprios.

Os grupos de interesse atuariam influenciando tanto o processo legislativo de formação das políticas regulatórias, quanto perante as próprias agências reguladoras com a finalidade de atender interesses pessoais. Portanto, conforme mencionado anteriormente, a regulação nem sempre será uma imposição de interesse unilateral do Estado, uma vez que, partindo dos pressupostos da teoria da captura a regulação pode ser realizada em razão do interesse da própria empresa regulada. Neste sentido, Posner (2004, p.57) explica que:

Essa teoria - que o termo "captura" descreve particularmente bem - afirma que com o passar do tempo as agências regulatórias acabam sendo dominadas pelo mercado regulado. Essa formulação é mais específica do que aquela da teoria geral dos grupos de interesse. Ela destaca um grupo de interesse em particular - as empresas reguladas - como prevalecente na batalha para influenciar legislação, e ela prevê uma sequência regular, na qual os propósitos originais do programa regulatório são posteriormente obstruídos por pressões dos grupos de interesse.

Porém apesar de possuir embasamento mais sólido do que a primeira versão, Posner afirma que mesmo a reformulação proposta por cientistas políticos é, em diversos aspectos, muito semelhante a algumas versões da teoria do interesse público e, inexiste fundamentação teórica que a sustente enquanto teoria, o que a faz ser insatisfatória como teoria da regulação. (POSNER, 2004, p. 57).

Posner propõe questionamento a respeito a quem captura a agência reguladora. A teoria apenas sustenta que o agente regulado pode realizar a captura da agência para que ela passe a atender aos seus interesses pessoais, porém não se questiona porque essa captura não pode ser feita pelos consumidores? O que faz com que essa classe não esteja apta a capturar as agências? É notório que os consumidores possuem tanto interesse em ter suas necessidades atendidas quanto às empresas reguladas, portanto Posner questiona que não há como se falar em captura apenas por um dos agentes e afastar esta possibilidade dos outros sem que sejam apresentadas justificativas (POSNER, 2004, p. 58).

Para que exista a regulação do mercado pressupõe-se a existência de uma ineficiência que justifique essa intervenção, neste sentido, a atuação da agência ocorre em busca de um equilíbrio de mercado. Para a teoria da captura a finalidade originária da regulação é substituída pelos objetivos impostos por grupos de interesse. Contudo, se a regulação realizada pela agência foi estabelecida em decorrência de uma necessidade do mercado e no decorrer 
do tempo houve um desvirtuamento de sua finalidade, conclui-se que o mercado irá permanecer carente de regulação e, eivado da mesma ineficiência que estava acometido antes da existência da agência (POSNER, 2004, p.57).

Neste sentido, o acolhimento da teoria da captura e a compreensão de que todas as agências não teriam como finalidade a busca por uma regulação econômica que atendesse ao interesse comum é tão intransigente quanto à afirmação de que a regulação sempre é utilizada com a finalidade de se alcançar o interesse coletivo. Assim como foi demonstrada a existência de agências capturadas, Posner (2004, p.57) também afirma que:

Uma porção significativa da regulação econômica atende aos interesses de associações de pequenas empresas, ou de instituições sem fins lucrativos, incluindo produtores de laticínios, farmacêuticos, barbeiros, caminhoneiros e, em especial, sindicatos de trabalhadores. Essas formas de regulação são totalmente inexplicáveis (e normalmente são ignoradas ou aplaudidas) nesta versão de grupos de interesse ou teoria da captura.

Contudo, afirmar a existência de regulação econômica que atenda aos interesses de consumidores e pequenos empresários não é o mesmo que falar de captura da agência por parte desses grupos que figuram como hipossuficiêntes. Apesar de Posner questionar porque essa captura não é realizada por consumidores, é importante destacar dois fatores importantes: o primeiro deles é que quanto maior é o grupo maior se tornam os custos de transação para que eles possam se organizar com determinada finalidade, o segundo aspecto a ser destacado é que a captura ocorre em decorrência do controle político e administrativo que as empresas reguladas têm sob as agências, o que não existe por parte dos outros grupos (POSNER, 2004, p. 58).

Posner também questiona o fato dos agentes econômicos apenas capturarem as agências, não utilizando sua influência para obter a criação de uma agência com o objetivo de alcançar seus interesses pessoais, ou até mesmo utilizar sua influência para atingir seus objetivos no âmbito do Poder Legislativo, o que tornaria a captura das agências desnecessárias, já que as próprias leis seriam criadas de acordo com os seus interesses (POSNER, 2004, p. 58).

Além de afirmar que nenhum desses questionamentos expostos é respondido pela teoria da captura, Posner ainda propõe a análise de três conjuntos de evidências, quais sejam: (i) nem sempre a captura é necessária, uma vez que não são todas as agências que são dotadas de integridade e honestidade; (ii) não é raro vislumbrar situações em que uma mesma agência regula mercados ou interesses conflitantes, ou seja, existem interesses de grupos concorrentes dentro de um mesmo mercado; (iii) e por fim, a teoria da captura ignora os diversos casos em que os interesses defendidos pelas agências são os dos grupos de consumidores (POSNER, 2004, p. 58).

Esses conjuntos de evidências ratificam as fragilidades da teoria e corroboram a afirmação de que a captura não pode ser considerada uma teoria, uma vez que inexiste qualquer fundamentação teórica ou comprovação empírica que a sustente. Contudo, ela pode ser entendida como um importante eixo que vincula a teoria do interesse público e a teoria econômica da regulação, que serão respectivamente apresentadas nos tópicos a seguir. 


\section{TEORIA DO INTERESSE PÚBLICO}

Os primeiros trabalhos que tratavam sobre regulação econômica sustentavam que a necessidade de regulação era advinda da existência de falhas de mercado. 0 Estado deveria agir de forma indireta para afastar a atuação de agentes nocivos e a perpetração de interesses pessoais. Assim seriam afastados os entraves para que o mercado fluísse de forma orgânica e obtivesse a maximização do bem estar social (CAMPOS, 2008, p. 283).

A propagação dessas ideias se tornou mais forte nos Estados Unidos após a crise de 1929 e da política do New Deal. A regulação era vista de forma positiva como um importante instrumento para afastar as falhas de mercado. Foi a partir da década de 1930 que essas correntes de pensamento se consolidaram e passaram a ser conhecidas como teoria do interesse público (SAMPAIO, 2013, p. 44).

A teoria recebeu esse nome em razão de seus defensores acreditarem que a regulação tinha como finalidade principal atender ao interesse público, sendo uma resposta aos anseios sociais e uma forma de intervir no mercado para solucionar suas falhas. São dois os pressupostos principais que fundamentam a teoria do interesse público. 0 primeiro deles afirma que os mercados são extremamente frágeis e estão dispostos a atuar de forma ineficiente. Já o segundo pressuposto afirma que o Estado possui um custo quase ínfimo para realizar a regulação (POSNER, 2004, p. 50).

A fragilidade dos mercados é sustentada pela afirmação de que esses são alvos de inúmeras falhas, o que faz com que exista uma ineficiência econômica. A atuação das agências reguladoras, segundo esta teoria, visa agir para afastar essas falhas. Neste sentido, o aumento da intervenção do Estado por meio da regulação seria diretamente proporcional ao crescimento da eficiência nos setores regulados (CAMPOS, 2008, p.284).

A assimetria de informações pode ser apontada como uma das falhas de mercado mais relevantes. Sobre essa falha, Campos (2008, p.287) explica que:

Em relação à assimetria de informação, é importante apontar que os modelos de competição de mercado se apoiam no pressuposto da informação perfeita em que os consumidores, ao tomarem sua decisão, sabem tudo o que precisam saber sobre a qualidade de um produto, preço da concorrência etc. Tal pressuposto não é realista porque obter informações tem custos, os produtos podem ser complexos ou seus efeitos somente serem sentidos no longo prazo ou, ainda, há efeitos colaterais desconhecidos.

A assimetria de informações significa a desigualdade de informações entre os polos da relação, o que poderá vir a beneficiar ou prejudicar um dos agentes. Dependendo do momento em que essa assimetria é identificada ela poderá ser classificada como seleção adversa ou moral hazard. A seleção adversa ocorre quando a diferença do grau de informação entre os agentes e o benefício de um deles em razão da superioridade informacional ocorre antes da transação ser realizada. Neste sentido, a falta de acesso a ampla informação faz com que o agente muitas das vezes tome decisões que não optaria se tivesse acesso a todas as informações (MACKAAY; ROUSSEAU, 2015, p. 136).

A assimetria de informações ex post ocorre por meio do moral hazard, também chamado de risco moral, que ocorre quando o agente econômico muda o seu comportamento após ter o seu bem protegido. Neste sentido, o exemplo mais disseminado diz respeito aos 
seguros de veículos, onde o agente após adquirir o seguro, passa a adotar condutas que elevam o risco de acontecer algum sinistro (MACKAAY; ROUSSEAU, 2015, p. 138).

Tendo em vista essas falhas de mercado e os pressupostos já mencionados, quais sejam, a expectativa do aumento da eficiência somado ao baixo custo a ser gasto pelo Estado, a regulação passa a ser vista como solução ideal para os problemas econômicos de diversos setores.

Contudo esses dois pressupostos citados como pilares da teoria são contestados por Posner (2004, p.51), que aduz que a regulação não está necessariamente vinculada às falhas de mercado e que "o conceito de governo como instrumento sem custos, fidedigno e efetivo de alteração do comportamento de mercado também já se desfez".

Conforme exposto anteriormente a teoria foi denominada dessa forma em razão da regulação ser entendida como uma resposta as demandas sociais em busca de uma economia que privilegie o interesse comum. Ocorre que os defensores desta teoria esquivaram-se de explicar qual seria esse "interesse comum" a ser perseguido. Falar em uma regulação que objetiva interesses sociais acaba se tornando vazio diante de uma sociedade plural.

A teoria do interesse público foi alvo de algumas reformulações, a primeira delas mantém a crença na importância e na probidade das agências reguladoras, porém reconhece que elas podem não obter a eficiência esperada, justificando que o vício não se encontra na estrutura das agências e nem na forma como ocorre a regulação, mas sim na ineficiência de seus funcionários e administradores. Neste sentido, Posner $(2004$, p.52) explica que a teoria reformulada sustenta "que as agências regulatórias são criadas para propósitos públicos idôneos, mas são mal administradas e, como resultado, os objetivos nem sempre são atingidos".

Posner (2004) segue mantendo sua discordância em relação à teoria e afirma que a reformulação não é satisfatória em decorrência de dois motivos. 0 primeiro deles aduz que a ineficiência regulatória pode ser um objetivo perseguido por grupos de interesse que possuem grande influência na criação da legislação que estabelece a política regulatória. Este argumento pressupõe que nem sempre a falta de efetividade da regulação será proveniente da forma como é desenvolvido o trabalho dentro da agência reguladora. As diretrizes de criação da agência podem ser suficientes para lhe afastar da regulação com o objetivo de privilegiar o interesse público.

É imperioso destacar que isso não se trata de um erro na formulação da estrutura da agência, mas sim diz respeito ao favorecimento de grupos que possuem forte influência no cenário político. Essa crítica pode ser diretamente relacionada à teoria da captura.

Neste sentido, Stigler (2004) de forma precisa observa que assim como a regulação pode ser imposta a uma indústria, ela também pode ser objetivada pela mesma, com a finalidade de utilizar a regulação econômica para alcançar seus próprios interesses. Portanto, assim como uma indústria pode ser escolhida como objeto de regulação, ela também pode escolher a regulação como instrumento.

O segundo motivo apontado por Posner (2004) revela que inexistem dados suficientes para que se afirme que existe uma má administração por trás das agências. A eficiência da agência é incentivada em razão da realização da distribuição orçamentária, ou seja, quanto melhor for o desempenho da mesma, maior será o montante destinado a ela. Além disso, o 
diretor possui a obrigação de prestar contas aos Poderes Executivo e Legislativo, o que faz com que ele busque demonstrar seu bom desempenho.

Não é apenas a cúpula das agências que se beneficiam em demonstrar sua eficiência, os demais funcionários também recebem incentivos para que sua atuação seja realizada da melhor forma possível. Apesar do seu desempenho não influenciar diretamente na sua remuneração, os funcionários que fazem parte do corpo de colaboradores de uma agência reguladora ganham visibilidade e aumentam sua valorização pessoal caso desejem migrar para a iniciativa privada, portanto, a eficiência da agência na qual faz parte também é um objetivo a ser perseguido por eles, mesmo que seja com a finalidade de agregar valor a si mesmo.

Posner (2004, p.54) afirma ainda que "outra objeção é que a agência tem poucos incentivos para minimizar custos porque, diferentemente de uma empresa privada, ela não pode manter os lucros oriundos da diminuição dos custos", porém esse argumento também não se sustenta, visto que inúmeros funcionários da iniciativa privada também não se beneficiam com o aumento do lucro das empresas nas quais fazem parte, entretanto, isto não se mostra como um incentivo para que eles passem a desempenhar suas atividades de forma inferior.

A teoria do interesse público passa por uma reformulação na qual Posner admite que existe a possibilidade de se considerar que a regulação realmente possui o interesse público como finalidade, porém ela é desempenhada de forma mal sucedida em razão de alguns fatores (POSNER, 2004, p. 54).

Por mais que se admita a regulação com finalidade inidônea, devem ser observados alguns obstáculos a sua realização eficiente. 0 primeiro deles diz respeito à inflação de atividades a serem desempenhadas pelas agências reguladoras, o que faz com que mesmo eivado de boa intenção esses órgãos não logrem êxito na realização de suas atividades.

O segundo aspecto que pode ser abordado como obstáculo à regulação eficiente é a precariedade da supervisão das agências pelo poder Legislativo, conforme afirma Posner (2004, p.55) ao revelar que "conforme a atividade do Legislativo aumenta, pode-se esperar uma crescente delegação de trabalho para as agências e um decrescente controle sobre estas agências".

Portanto, o crescente aumento das atividades desempenhadas pelas agências reguladoras, somado a precariedade de fiscalização destas por parte do Legislativo, acaba fazendo com que por mais bem intencionada que a regulação seja ela não consegue atingir seus objetivos de forma eficiente.

Thomas Merrill defende que inevitavelmente poderão ocorrer falhas por parte da Administração Pública e, que nestas situações deve acontecer a revisão da atuação administrativa pelo Poder Judiciário, porém ele ressalta que os Tribunais devem agir com cautela ao proceder à revisão da atuação da agência, uma vez que, em regra, as agências seriam melhores do que os Tribunais para alcançar o interesse público (MERRIL, 1997, p. 1049).

A teoria do interesse público foi eminentemente desenvolvida por economistas e apesar de sua formulação ser consistente é nítido a presença de diversas falhas. Em razão dos vícios apontados na teoria do interesse público foram desenvolvidas teorias explicativas que visavam sanar essas falhas. 
Conforme exposto, a teoria da captura surgiu como principal teoria explicativa decorrente da teoria do interesse público. Apesar de seus preceitos antagônicos, análise do risco de captura dos agentes reguladores pode ser usada até mesmo para ratificar a aplicabilidade da teoria do interesse público, caso seja demonstrada a inexistência de risco de captura.

Contudo, caso seja comprovada a existência de agentes capturados, conforme anteriormente exposto, a teoria da captura não possui substancial para ser considerada como uma teoria da regulação, neste sentido, foi necessária a realização de um aperfeiçoamento teórico resultando na teoria que será analisada no tópico seguinte.

\section{TEORIA ECONÔMICA DA REGULAÇÃO}

A fundamentação da teoria foi criada por George Stigler e publicada em um artigo no ano de 1971 denominado de "A teoria da regulação econômica", não apresentou, contudo, um nome para referir-se a ela. Em 1974 Richard Posner publicou um artigo tratando a respeito das teorias da regulação, dentre elas a teoria criada por Stigler, que passou a ser chamada por Posner de teoria econômica da regulação.

Sobre a teoria Peltzman (2004) afirma que:

O elemento mais importante dessa teoria é análise do comportamento político a partir dos parâmetros da análise econômica. Políticos, assim como qualquer um de nós, são considerados como maximizadores das suas próprias utilidades. Isso significa dizer que os grupos de interesse podem influenciar os resultados do processo regulatório ao fornecer apoio financeiro ou de outra natureza aos políticos ou reguladores (PELTZMAN 2004, p. 81).

Posner afirma que apesar da teoria também se afastar do pressuposto inidôneo da regulação e admitir a possibilidade de "captura" por grupos de interesse, além dos grupos que seriam compostos pelas empresas reguladas, ela não pode ser confundida com a teoria da captura, posto que para o autor "a teoria econômica é mais precisa e bem acabada - mais facilmente comparável e testável com um conjunto de dados empíricos - do que a teoria política". Neste sentido, a teoria econômica da regulação rejeita o suposto propósito virtuoso e probo da legislação, admite a possibilidade de captura por outros grupos de interesse que não a empresa regulada e substitui o termo "captura" por uma terminologia mais neutra de "oferta e procura" (POSNER 2004, p.59).

A teoria econômica da regulação é fundamentada em dois pressupostos:

A primeira é que dado que o poder coercitivo do governo pode ser usado para dar benefícios valiosos a indivíduos ou grupos específicos, regulação econômica - a expressão desse poder na esfera econômica - pode ser vista como um produto cuja alocação é governada por leis da oferta e da procura. A segunda idéia é que a teoria dos cartéis pode nos ajudar a identificar as curvas de oferta e procura. (POSNER, 2004, p.60)

Conforme já mencionado, o poder coercitivo do Estado é um dos seus maiores trunfos em relação à iniciativa privada, é ele que possibilita tanto as restrições impostas a empresas reguladas quanto à concessão de benefícios a elas. 
Stigler (2004) explica que são quatro os principais benefícios que o Estado pode conceder a uma indústria, sendo eles: subsídios em dinheiro, o controle sobre a entrada de novos concorrentes no mercado, o poder sobre os produtos substitutos e complementares (que são aqueles relacionados à atividade desenvolvida pela empresa) e o controle sobre a fixação de preços (STIGLER, 2004, p. 25).

A teoria dos cartéis é utilizada como exemplo para explicar as curvas de oferta e demanda por regulação. Sobre essa teoria Posner (2004, p. 60) explica que "o valor da cartelização é maior quanto menos elástica for à demanda pelo produto do mercado e mais cara, ou mais lenta for à entrada nesse mercado".

Neste sentido, Posner (2004, p. 61) entende que os principais custos que aumentam o valor da cartelização são os custos de transação para que os vendedores ajustem os valores a ser cobrados e a quantidade de produto que cada vendedor poderá vender e os custos de impor o acordo realizado pelo cartel para aqueles agentes que não estão participando ou para aqueles que desrespeitam o acordo. Nos países em que o cartel se configura como prática ilegal existe ainda o custo estimado referente à punição.

Apesar de ser citada como exemplo, a ocorrência de cartelização privada normalmente vai de encontro à necessidade de regulação. Isto porque quando o número de empresas é menor é consideravelmente mais fácil a realização do cartel, já que os custos de transação e os riscos de quebra do acordo também diminuem. Por outro lado, o inverso ocorre quando o número de empresas aumenta, tornando neste caso a regulação à solução mais viável e menos dispendiosa. Porém assim como a cartelização, a teoria econômica da regulação aponta que a regulação nestes casos também terá um custo (POSNER, 2004, p.61).

Diante do exposto, a teoria econômica da regulação pode ser usada para entender a grande incidência de legislação protecionista em áreas em que seria difícil a realização da cartelização privada (POSNER, 2004).

O maior diferencial da teoria econômica da regulação em face da teoria do interesse público e até mesmo dos pressupostos da teoria da captura, é a inclusão da política como um dos principais fatores que influenciam na regulação econômica. A regulação seria como um bem ofertado pelos políticos, que oferecem os benefícios que somente o poder público poderia oferecer, desde que os agentes econômicos estejam dispostos a arcar com o preço exigido pelos políticos (POSNER, 2004, p.63).

Neste sentido, a teoria adota os preceitos da racionalidade econômica para explicar que os políticos, mesmo investidos em cargos públicos, são indivíduos que buscam a maximização de seus interesses próprios.

Posner destina grande parte da sua análise da teoria econômica da regulação a constatação de evidências empíricas que sustentam a teoria, porém, o autor também não se esquiva de apresentar as falhas presentes neste corpo de evidências (POSNER, 2004, p.70).

Portanto, o suporte empírico apresentado pelas teorias da regulação tem papel de destaque na análise realizada por Posner, o que torna necessária uma exposição mais detalhada sobre o tema. 


\section{A INSUFICIÊNCIA DE SUPORTE EMPÍRICO NAS TEORIAS DA REGULAÇÁO}

As teorias da regulação e os pressupostos da captura regulatória possuem uma fragilidade como ponto de interseção, qual seja, a insuficiência de suporte empírico. Uma breve leitura da análise realizada por Posner revela em diversos momentos sua inquietação quanto à carência de estudos empíricos no que tange a regulação econômica, o que levou o autor a concluir que nenhuma teoria foi suficientemente apurada para que pudesse gerar hipóteses precisas passíveis de verificação empírica (POSNER, 2004, p. 74).

No decorrer deste trabalho já foram mencionados alguns aspectos em que Posner revela essa insuficiência de suporte empírico, contudo, torna-se necessário reservar uma seção para análise do tema, uma vez que esta pode ser apontada como uma fragilidade presente em todas as abordagens de regulação analisadas por Posner.

Contudo, antes de adentrar a seara da regulação econômica, cabe ressaltar que no âmbito do Direito, de forma geral, existe uma escassez de estudos empíricos. Apesar da inexistência de uma teoria central compartilhada do direito ser um entrave a verificação de hipóteses de forma universal, os trabalhos empíricos ocupam um papel importante de revelar como se da o comportamento humano diante das diversas normas jurídicas. Neste sentido, apesar de ainda ser escasso, o reconhecimento da sua importância fez com que paulatinamente o trabalho empírico venha ocupando espaço dentro do conhecimento jurídico (ULEN; COOTER, 2014, p.62-63).

A importância da comprovação empírica se ratifica no âmbito da regulação com o não reconhecimento da captura como teoria, uma vez que, Posner (2004, p. 57) conclui que a captura é "uma hipótese desprovida de qualquer fundamento teórico", o inviabiliza a existência de técnicas de validação empírica.

Inexiste qualquer comprovação da interação entre as agências reguladoras e as empresas reguladas (POSNER, 2004, p.57). A ausência de comprovação da hipótese de captura, somada aos conjuntos de evidências já expostos, que revelam diversas situações inexplicadas pela teoria da captura, demonstram a insuficiência da teoria.

No que tange as teorias da regulação, apesar de serem manifestamente reconhecidas como teorias, também se revelam com suporte empírico insuficiente.

Alguns preceitos expostos como verídicos pela teoria do interesse público carecem de comprovação empírica, como por exemplo, as afirmações de que as agências reguladoras são mal administradas ou que sejam menos eficientes que outras organizações. (POSNER, 2004, p. 52-53).

Um dos fatores que fez com que a teoria econômica da regulação fosse reconhecida como a que detêm melhor embasamento teórico foi o seu suporte empírico. Neste sentido, Posner (2004, p. 67) exemplifica que:

Existe um número substancial de estudos de caso - companhias de transporte rodoviário, aéreo, ferroviário e muitos outros mercados - que sustenta a ideia de que a regulação econômica é mais bem explicada como um produto fornecido a grupos de interesse do que como uma expressão do interesse social em eficiência jurídica. 
Contudo, conforme exposto anteriormente, apesar da teoria econômica ser considerada por Posner a teoria da regulação com melhor embasamento e suporte, esta não está livre de falhas. Neste sentido, Posner apresenta seis fragilidades presentes no corpo de evidências empíricas que sustenta a teoria (POSNER, 2004, p. 70).

A primeira falha aduz que a maior parte das evidências é compatível com qualquer versão da teoria dos grupos de interesse. A distinção entre a teoria do interesse público e a teoria econômica da regulação pode ser facilmente realizada, porém essa distinção se dificulta ao confrontá-la com qualquer teoria que tenha como base a teoria dos grupos de interesse. Neste sentido, Posner (2004, p.70) afirma que:

Para que esses estudos de caso sustentem a teoria econômica da regulação, eles teriam que demonstrar que as características e circunstâncias dos grupos de interesse foram tais que a teoria econômica teria previsto que eles, e não outros grupos, obteriam a regulação da qual se beneficiariam.

A segunda evidência relata que a pesquisa empírica não está ocorrendo de forma sistemática, ou seja, os casos apontados como exemplo da teoria são escolhidos justamente em razão de suas peculiaridades propícias a aplicação da mesma. Os estudos a respeito da teoria foram realizados, eminentemente, a partir da análise de estudos de casos, que não foram selecionados de forma aleatória, mas sim a partir das suas similitudes com os preceitos defendidos pela teoria. Essa fragilidade não invalida os estudos já realizados, contudo aponta a necessidade de realização de pesquisa empírica mais sistemática (POSNER, 2004, p.70).

A terceira evidência alega que alguns estudos de casos de regulação têm produzido evidências difíceis de serem relacionadas à teoria econômica. Destaca-se ainda que a teoria não aborda a possibilidade de fracassos na tentativa de regulação, o que inevitavelmente pode vir a ocorrer (POSNER, 2004, p.71).

A quarta falha apontada ocorre em razão das evidências empíricas dependerem fortemente de uma rejeição confiante das justificativas de interesse público. A teoria econômica rejeita a justificativa de que a regulação pode ser realizada com a finalidade de obtenção de interesse público, porém a teoria não explica porque inexiste esta possibilidade, assim como também se esquiva de justificar o motivo que enseja a criação de toda a legislação regulatória de acordo com o que dispõe a teoria econômica (POSNER, 2004, p. 72).

A dificuldade em rastrear os efeitos da regulação econômica é a quinta falha apresentada por Posner, que revela como efeito colateral da regulação a dificuldade em revelar quais mercados são beneficiados ou prejudicados em razão dessa intervenção do estado (POSNER, 2004, p. 73).

Por fim, na sexta crítica Posner aduz que não há explicação para a retórica usada pela teoria do interesse público para expor o processo de elaboração de políticas públicas. A introdução de teorias de fraude, ou mais amplamente de custos de informação sugerem um reavivamento da teoria do interesse público de uma forma que ela possa até mesmo ser testada empiricamente (POSNER, 2004, p. 73).

A partir desta análise realizada por Posner é possível perceber que a maior parte das fragilidades expostas são passíveis de ajuste a partir de um aprofundamento da teoria. Neste sentido, a teoria econômica se sustenta não só em razão do seu robusto arcabouço de emba- 
samento empírico, mas também porque a partir da constatação das suas falhas é possível propor um aperfeiçoamento da teoria.

\section{CONSIDERAÇÓES FINAIS}

Uma breve análise das teorias da regulação torna perceptível a complexidade com que a regulação econômica se desenvolveu no decorrer de um século. A abordagem sob a perspectiva da economia se tornou apenas o ponto de partida do estudo da regulação, que agregou como necessária a pesquisa interdisciplinar em áreas como ciências políticas, direito e até mesmo psicologia comportamental.

O presente trabalho teve como finalidade explicar a teoria do interesse público e as críticas dela decorrentes, que fizeram com que fossem elaboradas mais duas teorias explicativas, com finalidade de expor e propor soluções para os vícios presentes na teoria do interesse público.

A teoria da captura foi a mais importante que surgiu em oposição aos "problemas" da teoria do interesse público, tendo em vista que ela se opõe a ideia de "bem comum" e de que a regulação seria realizada com a finalidade de se alcançar um interesse público. Contudo, apesar de parecer mais próxima da realidade do que a teoria do interesse público, a teoria da captura também foi alvo de críticas o que fez com que ela sofresse uma reformulação que resultou na teoria econômica da regulação.

Contudo, é notória a importância da captura no que tange a regulação econômica, uma vez que, por mais que não possua o status de teoria da regulação, a análise a partir de sua perspectiva é o que possibilita uma completa dissecação das demais teorias regulatórias que foram abordadas no presente trabalho.

A comprovação da inexistência da captura das agências demonstraria a consistência do embasamento da teoria do interesse público, fazendo com que mesmo que se constate que a captura não exista, os estudos a partir dela se tornam indispensáveis para a análise do mercado regulado.

Assim como a constatação da existência da captura não tornaria possível a aplicação da teoria primordialmente elaborada, tendo em vista que pelos motivos expostos é imprescindível um refinamento para que esta se configure como uma teoria regulatória, o que ocorreu a partir da reconfiguração que deu origem a teoria econômica da regulação.

O risco da captura dos agentes reguladores deve ser analisado conforme o cenário de cada Estado, já de depende de fatores variáveis como obviamente o mercado e até mesmo a política.

No Brasil a presença marcante de um modelo capturado está diretamente relacionada ao controle político e administrativo que os grupos de interesse possuem nas agências e até mesmo no Poder Legislativo. Neste cenário, a compreensão de como se dá a captura e quais os motivos que fazem com que os agentes públicos sejam capturados é fundamental para que se verifique de que forma podem ser solucionadas as falhas de mercado e as falhas de governo possibilitando uma regulação mais eficiente. 
Neste aspecto é notória a importância da Análise Econômica do Direito como ferramental teórico para aplicação da captura como eixo de análise.

Apesar da busca pelo aperfeiçoamento, todas as teorias estão eivadas de falhas e, o presente trabalho utiliza da abordagem de Posner (2004) para expor os pontos centrais de cada teoria e as principais críticas que o autor destina a cada uma delas. Contudo, também se buscou a partir de uma perspectiva própria demonstrar a importância da análise da captura independentemente da teoria abordada.

Na realidade Posner (2004, p. 74) defende que nenhuma das teorias da regulação objeto do presente trabalho possuem suporte empírico significativo. Todas elas não foram testadas o suficiente para que pudessem ser verificadas empiricamente, contudo, não há qualquer hesitação em afirmar que dentre as teorias explanadas, a teoria econômica da regulação é a que mais se aproxima da eficiência pretendida, até mesmo porque ela considera um fator que até o momento era ignorado pelas demais teorias, que é a análise do comportamento humano e da racionalidade dos indivíduos.

\section{REFERÊNCIAS}

CAMPOS, Humberto Alves de. Falhas de Mercado e Falhas de Governo: Uma Revisão da Literatura sobre Regulação Econômica. Brazilian Journal of International Law, vol.5, no. 2, July/December 2008, pp. 281.

GUERRA, Sergio. Agencias reguladoras: da organização administrativa piramidal à governança em rede. Belo horizonte: Fórum, 2012.

JAKIBI, Karin Bergit; RIBEIRO, Marcia Carla Pereira. Análise econômica do direito e da regulação do mercado de capitais. São Paulo: Atlas, 2014.

MACKAAY, Ejan; ROUSSEAU, Stéphane. Análise econômica do direito. 2. Ed. São Paulo: Atlas, 2015.

MERRILL, Thomas W. Capture Theory and the Courts: 1967-1983. Chicago-Kent Law

no. 1, 1972, pp. 207.

OLIVEIRA, Rafael Carvalho Rezende. Novo perfil da regulação estatal: Administração Pública de resultados e análise de impacto regulatório. Rio de Janeiro: Forense, 2015.

PEDRO, Luis Antonio Velasco San. Economic Regulation and Competition. Acta Universitatis Lucian Blaga, vol. 2012,no. 2, 2012, pp. 166.

PELTZMAN, Sam. A teoria econômica da regulação depois de uma década de desregulação, trad. Tiago Machado Cortez. In: MATTOS, Paulo. Regulação Econômica e Democracia- O debate Norte-Americano. São Paulo: Editora 32, 2004.

POSNER, Richard A. Teorias da regulação econômica, trad. Mariana Mota Prado. In: MATTOS, Paulo. Regulação Econômica e Democracia- O debate Norte-Americano. SãoPaulo: Editora 32, 2004.

PRITCHETT, C. Herman. Economic Regulation. American Constitutional Issues. New York, McGraw-Hill.

SAMPAIO, Patrícia Regina Pinheiro. Regulação e concorrência- A atuação do CADE em setores de infraestrutura. São Paulo: Saraiva, 2013.

SANSON, Alexandre. Os grupos de pressão e a consecução das políticas públicas. In: SMANIO, Gianpaolo Poggio. BERTOLIN, Patrícia Tuma Martins. O Direito e as Políticas Públicas no Brasil. São Paulo: Atlas, 2013, p. 117-138.

STIGLER, George J. A teoria da regulação econômica, trad. Emerson Ribeiro Fabiani. In: MATTOS, Paulo. Regulação Econômica e Democracia- O debate Norte-Americano. São Paulo: Editora 32, 2004. 
STIGLER, George J. The Process of Economic Regulation. Antitrust Bulletin, vol. 17, Review, vol. 72, no. 4, 1997, pp. 1039.

TULLOCK, Gordon; SELDON, Arthur; BRADY, Gordon L. Falhas de governo: uma introdução à teoria da escolha pública. Rio de Janeiro: Instituto liberal, 2005.

ULEN, Thomas; COOTER, Robert. Um prêmio Nobel para a ciência jurídica: teoria, trabalho empírico e o método científico no estudo do direito. In: PORTO, Antônio Maristrello; SAMPAIO, Patrícia (org.). Direito e Economia em dois mundos: doutrina jurídica e pesquisa empírica. Rio de Janeiro: Editora FGV, 2014.

WILEY JR, John Shepard. A Capture Theory of Antitrust Federalism. Harvard Law Review, vol. 99, no. 4, February 1986, pp. 713.

Recebido/Received: 08.07.2020.

Aprovado/Approved: 21.11.2020. 